Taurus-Littrow valley floor, Geochim. Cosmochim. Acta, Suppl. 6, 2463-2482, 1975.

Wood, C. A., and L. Andersson, New morphometric data for fresh lunar craters, Geochim. Cosmochim. Acta, Suppl. 10, 3669-3689, 1978.

Wood, C. A., and J. W. Head, Comparison of impact basins on Mercury, Mars, and the Moon, Geochim. Cosmochim. Acta, Supp1. 7, 3626-3651, 1976.

Wood, C. A., J. W. Head, and M. J. Cintala, Interior morphology of fresh martian craters: the effect of target characteristic, Geochim. Cosmochim. Acta, Supp1. 10, 3691-3705, 1978.

Wood, J. A., J. S. D1ckey, Jr., U. B. Marvin, and B. N. Powell, Lunar anorthosites and $a$ geophysical model of the Moon, Geochim. Cosmochim. Acta, Supp1. 1, 965-988, 1970.

Young, R. A., The lunar impact $¥$ lux, radiometric age correlation, and dating of specific lunar features, Geochim. Cosmochim. Acta, Supp 1. 8, 3457-3473, 1977.

Young, R, A., Mare crater size-frequency distributions: Implications for relative surface ages and regolith development, Geochim. Cosmochim, Acta, Suppl, 6, 2645-2662, 1975,

Zisk, S, H, C, A, Hodges, H, J, Moore, $\mathrm{R}_{2} \mathrm{~W}$, Shorthill, T, W, Thompson, E, A, Whitaker, and D. E, Wilhelms, The Aristarchus-Harbinger region of the Moon: surface geology and history from recent remote-sensing observations, The Moon, 17, 59-99, 1977 .

Fortunately for those who wish to keep abreast of overall developments in planetary geology, results of space missions are genera1ly clustered in single issues of a journal. Mariner 9 results are reported in the Journal of Geophysical Research ( $V, 78$, no, 20, 1973). Mariner 10 results are also in the J.G.R. (V. 80 , no. 17, 1975). Viking primary-mission results are in the J,G.R. (V, 82, no, 28, 1977),

There are several book-length reviews of the Moon with special emphasis on the development of the surface features (Mutch, 1972; Schultz, 1976). Wilhelms (1970) and Wilhelms and McCauley (1971) have summarized the extensive lunar mapping program of the U, S. Geological Survey. A general review of Martian surface geology is contained in Mutch et al. (1976).

There have been a large number of photographic collections produced, most of them as NASA special publications. Two worthy of special note are The Atlas of Mercury (Davies et al., 1978) and The Ifartian Landscape (Viking Lander Imaging Team, 1978).

\title{
PLANETARY ATMOSPHERES
}

Andrew P。Ingerso11, Anthony R. Dobrovolsk1s, and Bruce M. Jakosky

Division of Geological and Planetary Sciences, Californla Institute of Technology Pasadena, California 91125

Introduction

Four years is approximately the doubling time for knowledge of extra-terrestrial planetary atmospheres. During 1975-8 the results of several important missions to Venus, Mars, Jupiter and Its satellites were analyzed, and during 1979 more spacecraft will arrive at Jupiter and Saturn. Spacecraft data are supplemented by ground-based observations, often at higher spectral resolution and extending over longer periods of time. As a result of this rapid growth of information, many first-order questions concerning the composition, physical state and kinematics of planetary atmospheres have been answered. Second-order hypotheses concerning chemical kinetics, heat and momentum transports, dynamics, history and evolution will soon be tested by comparing the output of quantitative models to direct observation.

The bibllography accompanying this review covers the published literature through 1978. Journals that plan special issues in 1979 covering specific spacecraft missions include Journal

Copyright 1979 by the American Geophysical Union. of Geophysical Research (extended Viking mission to Mars, two Issues), Science (Pioneer Venus encounter in December 1978, two 1ssues, Voyager encounters with Jupiter in March and July 1979, two 1ssues), Soviet Astronomy Letters (Venera 11 and 12 encounters in December 1978, one issue). Results gleaned from press releases following the Ploneer Venus and Voyager encounters have been included in some cases, accompanted with warnings that they are subject to change.

The material is presented in order of increasing distance from the sun: Venus, Mars, Jupiter, outer planets and satellites. The earth's atmosphere is beyond the scope of this review, but as the new phase of planetary atmospheres research continues, major generalizations that include the earth are likely to emerge, and some accepted theories developed for the earth are likely to fa11.

\section{Venus}

The atmosphere of Venus is $95 \%$ or more $\mathrm{CO}_{2}$ (molar fraction), with a surface pressure of about 90 bar. The bulk of the remaining gas is 
$\mathrm{N}_{2}$, with an abundance of about 1-5\% [Surkov, 1977; Hoffman et al., 1979; Oyama et a1., 1979]. The fractions (in parts per million) of $\mathrm{H}_{2} \mathrm{O}, \mathrm{SO}_{2}, \mathrm{O}_{2}$, Ar and $\mathrm{Ne}$ are 1000-5000, 100-500, 60-70, 20-100, and 5-100, respectively. These numbers may be refined in the published reports that are now in press; identifications of additional gases are also likely.

The noble gas isotopic composition measured by the Ploneer Venus and Venera 11 and 12 probes is a major new result. In particular, the roughly 100 -fold excess of $\mathrm{Ne}^{20}, \mathrm{Ar}^{36}$ and $\mathrm{Ar}^{38}$ relative to the earth seems to imply gross differences in the solar nebula between the earth and Venus at the time of planetary formation. For comparison, the abundances of $\mathrm{N}_{2}, \mathrm{CO}_{2}$ and $\mathrm{Ar}^{40}$ (produced from the decay of $\mathrm{K}^{40}$ in the planetary interfor) are comparable for the earth and Venus, provided the $\mathrm{CO}_{2}$ bound in sedimentary rocks on earth is included in the inventory. The Implications of the noble gas abundances have yet to be sorted out. Perhaps the discussion will provide answers to another long-standing question, the thousand-fold depletion of free water on Venus relative to the earth [see, for example, Walker, 1975].

The vertical structure of the Venus atmosphere from 0-68 km altitude may be summarized on the basis of Venera $8,9,10$ measurements [Keldysh, 1977] and some preliminary results from Pioneer Venus: From the surface $(T \sim 740 \mathrm{~K}, \mathrm{P} \sim 90$ bars) to $35 \mathrm{~km}$ altitude ( $\mathrm{T} \sim 430 \mathrm{~K}, \mathrm{P} \sim 5$ bars), the atmosphere is practically devold of aerosol [Marov et al., 1976]. The temperature lapse rate is between $90 \%$ and $100 \%$ of the adiabatic value [Avduevskil et al., 1976a]. The downward light flux varies linearly with pressure in this altitude range, consistent with conservative molecular scattering. The Venera 9 and 10 probes near the sub-solar point measured a surface light flux of $100 \mathrm{~W} \mathrm{~m}^{-2}$ [Avduevskil et al., $1976 \mathrm{c}]$; the Pioneer Venus probe at $67^{\circ}$ solar zenith angle measured $15 \mathrm{~W} \mathrm{~m}^{-2}$ [Tomasko et al., 1979], a result which is roughly consistent with the Venera measurement. Between about $35 \mathrm{~km}$ and $49 \mathrm{~km}$ altitude $(\mathrm{T} \sim 350 \mathrm{~K}, \mathrm{P} \sim 1.5 \mathrm{bar}$ ), a thin haze of $\sim 1 \mu \mathrm{m}$-sized particles is present in low concentrations $\left(\mathrm{N} \sim 1 \mathrm{~cm}^{-3}\right)$, and the lapse rate is $80 \%$ of the adiabatic value. The base of the main cloud is at $49 \mathrm{~km}$; within this cloud the concentration $\mathrm{N}$ is about $100 \mathrm{~cm}^{-3}$, the lapse rate is adiabatic, the particle diameter is about $10 \mu \mathrm{m}$, and the optical extinction coefficient is in the range 1-3 $\mathrm{km}^{-1}$ [Marov et al., 1976; Knollenberg and Hunten, 1979]. Above $58 \mathrm{~km}$ ( $\mathrm{T} \sim$ $275 \mathrm{~K}, \mathrm{P} \sim 300 \mathrm{mb}$ ) the lapse rate is $50 \%$ of the adiabatic value, and the particles are dielectric spheres $(\mathrm{r} \sim 1.05 \mu \mathrm{m}, \mathrm{n} \sim 1.44)$ reaching unit optical depth $(T \sim 1)$ at $68 \mathrm{~km}(\mathrm{~T} \sim 230 \mathrm{~K}$, $P \sim 50 \mathrm{mb}$ ) a Much indirect evidence points to sulfuric acid $\left(85 \% \mathrm{H}_{2} \mathrm{SO}_{4}, 15 \% \mathrm{H}_{2} \mathrm{O}\right)$ as the main cloud consituent; elemental sulfer is a leading candidate for the larger particles seen in the cloud [Hapke and Nelson, 1975; Young, 1977].

The relatively high light levels at the surface suggest that sunlight maintains the high temperatures. Although the optical depth at the surface is large ( $\left.\tau_{\text {vis }} \sim 30\right)$, the particle albedo is also large $\left(\bar{\omega}_{0} \sim 0.999\right)$, and light is able to penetrate the atmosphere by diffusion [Marov et al., 1976]. Weak, allowed transitions of $\mathrm{CO}_{2}, \mathrm{H}_{2} \mathrm{O}, \mathrm{SO}_{2}$, and possibly other gasses provide the high Infrared opacity below $49 \mathrm{~km}$ [Pollack and Young, 1975]. The main cloud prodives the high infrared opacity $\left(\tau_{I R} \sim 7\right)$ from 49 to $68 \mathrm{~km}$. If this opacity source were removed, the atmosphere would cool by $100-200 \mathrm{~K}$ in several years. The Venus climate is thus extremely sensitive to trace gases and condensates in concentrations $<10^{-3}$.

Dynamics plays a major role in maintaining the lapse rate close to the adiabatic value and in redistributing heat from day to night. The day side temperature is some $30 \mathrm{~K}$ greater than the night side temperature at altitudes above $55 \mathrm{~km}$ [Yakovlev et al., 1976]. In addition, polar temperatures are greater than equatorial temperatures in the Venus stratosphere [Taylor et a1., 1979]. The nature of the circulations that balance radiative sources and sinks is not known at present, although ultraviolet cloud motions suggest a symmetric meridional circulation [Suomi and Limaye, 1978].

The wind profiles measured by Veneras 8,9 , and 10 (Fig. 1) confirm the existence of a high
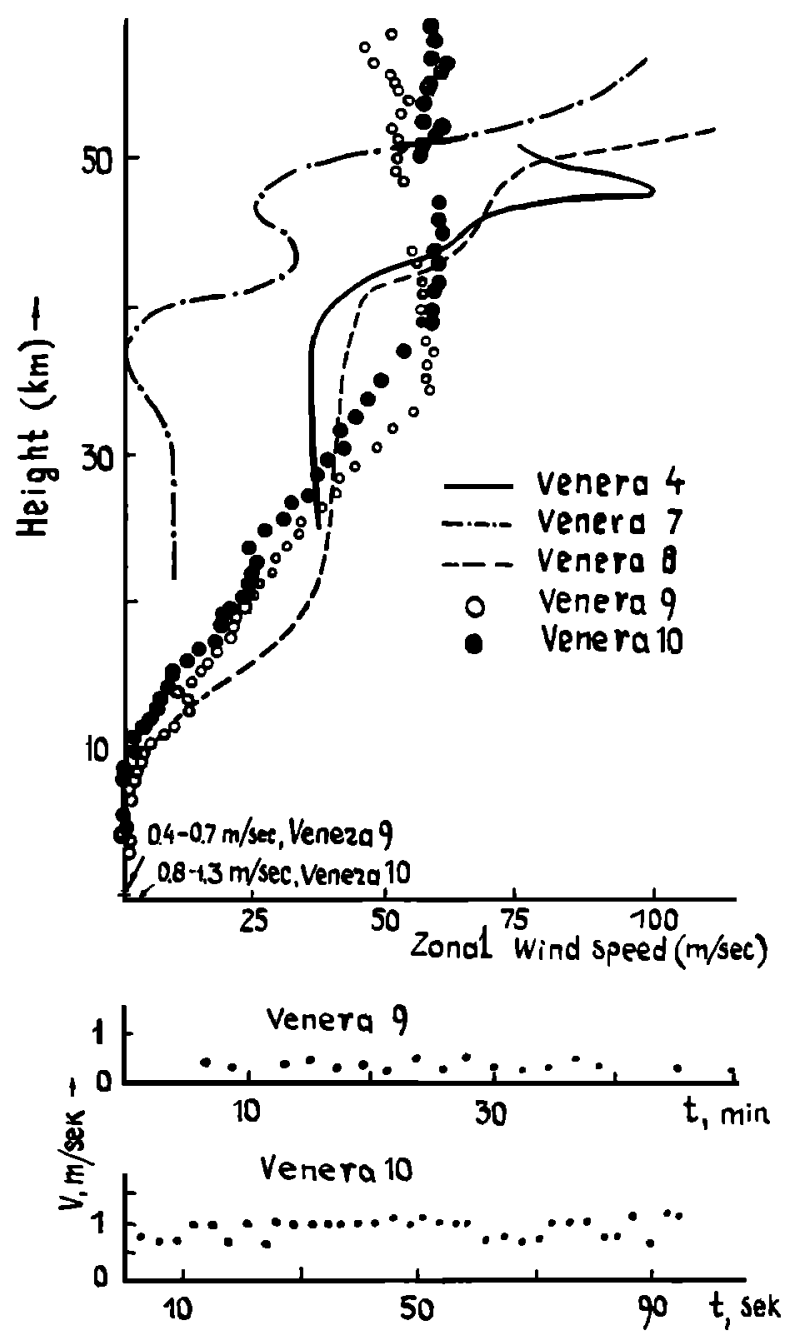

Fig. 1. Atmospheric and surface-wind velocities derived from the Doppler-shifted radio signal (Venera $4,7,8,9$, and 10 landers, top) and anemometric measurements (Venera 9 and 10 landers, bottom). From Marov (1978). Courtesy of Annual Reviews, Inc. 
speed $\left(v \sim 100 \mathrm{~ms}^{-1}\right)$ zonal circulation in the same direction as the planet's rotation (retrograde). Velocitles above $40 \mathrm{~km}$ altitude are somewhat greater on the morning side (Venera 8) where the mean wind is toward the subsolar point, than on the afternoon side (Venera 9 and 10) where the mean wind is away from the subsolar point. Further, ground-based spectroscopic observations suggest that the zonal wind drops to low values in the altitude range 60-65 km [Crisp and Young, 1978]. Such a reversal of zonal velocity gradient is also Implied by the higher polar stratospheric temperatures observed by Pioneer Venus [Taylor et al., 1979]. The momentum source of the $100 \mathrm{~ms}^{-1}$ wind has not been conclusively identifled, although several reasonable mechanisms (vertically propagating tides and waves, longltudinally varying eddies, mean meridional circulations, etc.) have been suggested [see Schubert et al., 1977, for a review]。 Thermally-driven atmospheric tidal torques seem capable of balancing the gravitationally-driven body tidal torques so as to maintain the spin of Venus at 1 ts current value [Ingersoll and Dobrovolskis, 1978].

The Ionosphere of Venus shows strong diurnal behavior, with peak electron densities on the day side of (1-3) $\times 10^{5} \mathrm{~cm}^{-3}$ near $140 \mathrm{~km}$ altitude [Fjeldbo et a1., 1975; Yakovlev et al., 1976]. The airglow spectrum is dominated by $\mathrm{CO}_{2}$ and its dissociative products [Krasnopo1'ski1 et a1., 1976; S1ysh, 1976]. The exospheric temperature is approximately $400 \mathrm{~K}$ in the daytime, dropping to $100 \mathrm{~K}$ at night [Bertaux et a1., 1976; Keating et a1., 1979], and there exists a hydrogen corona out to $5500 \mathrm{~km}$ on the night side [Bertaux et a1., 1976]. The dynamics of the upper atmosphere [Dickinson and Ridley, 1975, 1977] and the Ionosphere-solar wind interaction [Bauer et al., 1977] may be important for determining temperatures and composition in these regions.

\section{Mars}

The molar fractions of $\mathrm{CO}_{2}, \mathrm{~N}_{2}, \mathrm{Ar}$, and $\mathrm{O}_{2}$ as measured by V1king are $0.956,0.027,0.016$, and 0.001 respectively. The isotopic ratios $\mathrm{c}^{12} / \mathrm{C}^{13}$ and $0^{16 / 0^{16}}$ are the same for earth and Mars. The ratio $\mathrm{N}^{14} / \mathrm{N}^{15}$ is lower for Mars by a factor 0,50 , and the ratios $\mathrm{Ar}^{40} / \mathrm{Ar}^{36}$ and $\mathrm{Xe}^{129} / \mathrm{Xe}^{\mathrm{i} 32}$ are higher by factors of 102 and 2.6, respectively [Owen et al., 1977]. The ratios of non-radiogenic noble gases to total planetary mass form a monotonic sequence, decreasing by a factor of 100 from Venus to earth and again by the same amount from earth to Mars. On the other hand, the relative abundance pattern of the noble gases on Mars is similar to that on earth (Fig. 2). One model [Anders and Owen, 1977] proposes that Mars was deficient in noble gases at the time of planetary formation, and that subsequent outgassing (as measured by $\mathrm{Ar}^{40}$ ) was less complete.

The high $\mathrm{N}^{15} / \mathrm{N}^{14}$ ratio on Mars has been explained as the result of diffusive separation in the upper atmosphere followed by photochemical escape [McElroy et al., 1976a]. An amount of nitrogen equal to 10 times the present amount would have to have escaped, assuming a terrestrial value of the $\mathrm{N}^{15 / \mathrm{N}^{14}}$ ratio initially.

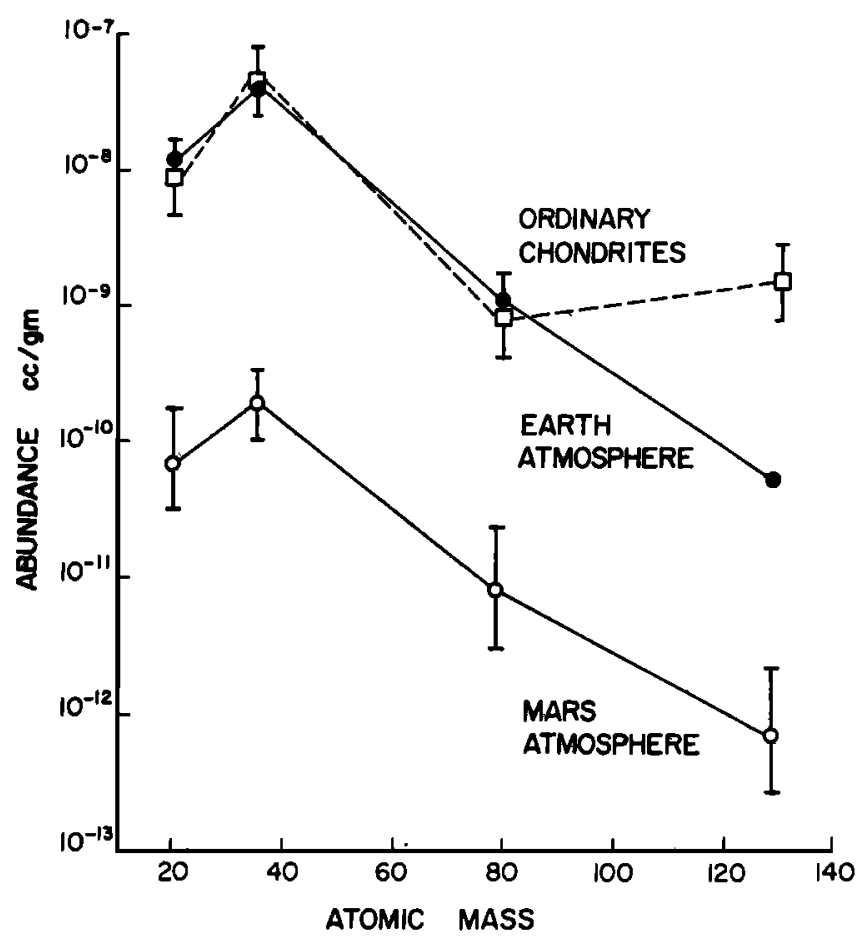

Fig. 2. Abundances of noble gases in ordinary chondrites and in the atmospheres of the earth and Mars. Abundances are in cubic centimeters per gram (at STP) of planet (or meteorite). From Owen et al. (1977). Courtesy of American Geophysical Union.

Th1s brings the ratio of total $\mathrm{N}_{2}$ to $\mathrm{Ar}^{40}$ more In line with the earth and Venus [Anders and Owen, 1977]. Using the earth's $\mathrm{N}_{2} / \mathrm{Ar}^{4} / \mathrm{CO}_{2} / \mathrm{H}_{2} \mathrm{O}$ as a guide, the abundances of $\mathrm{CO}_{2}$ and $\mathrm{H}_{2} \mathrm{O}$ originally present on Mars are then 200 and $1000 \mathrm{~g} \mathrm{~cm}^{-2}$, respectively [Owen et al., 1976]. These volatiles may be bound at present in the Martian regolith or polar caps [Fanale, 1976]. No organic molecules are present in the soll in amounts greater than a few parts per billion [Btemann et a1., 1977].

The Viking orbiters established that the residual north polar cap in summer is composed of low albedo water ice [K1effer et al., 1976a; Farmer et a1., 1976]. The south polar cap in summer is more of a mystery, but the low temperatures $(T \leq 165 \mathrm{~K})$, low water vapor abundances, and transient behavior of the receding cap in spring [James et al., 1979] suggest that $\mathrm{CO}_{2}$ frost can survive the summer. This unanticipated result leaves open the question of whether the Martian atmospheric pressure is controlled by vapor equilibrium with solid $\mathrm{CO}_{2}$ [Leighton and Murray, 1966], $\mathrm{CO}_{2}-\mathrm{H}_{2} \mathrm{O}$ clathrate [Dobrovolskis and Ingersol1, 1975], or adsorbed $\mathrm{CO}_{2}$ [Fanale and Cannon, 1978].

Temperatures in the atmosphere reveal substantial departures from radiative equilibriuth at all altitudes (Fig. 3), a cold Ionosphere ( $<200 \mathrm{~K}$ at 120-200 km altitudes), and substantial tidal oscillations at both Viking lander sites. Anomalously low surface temperatures, as much as $15 \mathrm{~K}$ below the $\mathrm{CO}_{2}$ frost point, were observed at the winter poles, and may reflect an enrichment of non-condensable gases as $\mathrm{CO}_{2}$ is removed [Kieffer et al., 1977]. Sudden stratospheric 

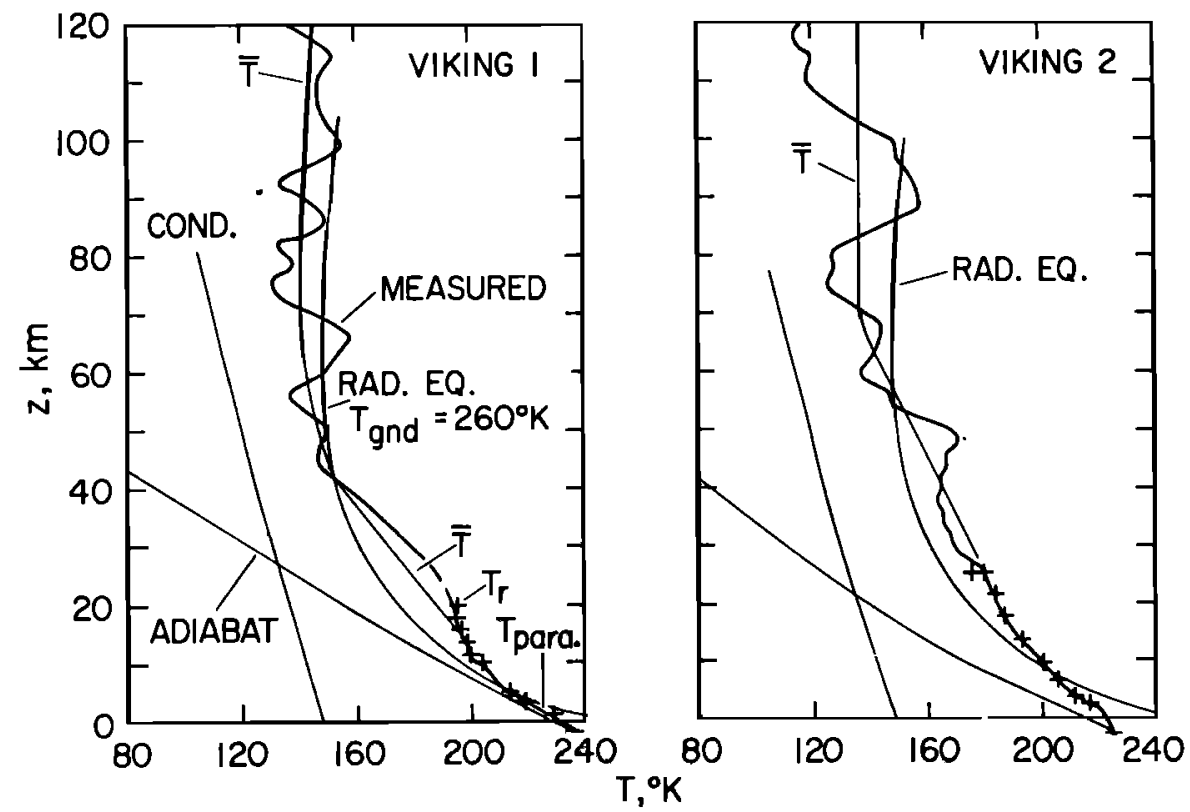

Fig. 3. Atmospheric temperature profiles for Mars below $120 \mathrm{~km}$ from Viking 1 and 2. From Seiff and Kirk (1977)。 Courtesy of American Geophysica1 Union。

warmings $(\Delta T=50 \mathrm{~K})$ over the winter pole were observed at the time of the global dust storms [Martin and Kieffer, 1979]. During these storms, the optical depth at the surface was observed to rise from about 0.5 to greater than 3 [Pollack et al., 1979]. The Viking mission brought out the extreme sensitivity of the Martian climate to global dust storms [Briggs et a1., 1977].

The Viking lander observations of winds, temperatures, and pressures near the Martian surface represent the most complete meteorological time series for any planetary atmosphere besides the earth's. This record displays diurnal cycles, transient weather patterns, seasonal effects, and responses to global dust storms [Hess et al., 1976, 1977, 1979; Ryan et a1., 1978], which permit testing theories of boundary layer processes, 1ocal topographic forcing [Webster, 1977; Mass and Sagan, 1976], global tidal oscillations [Zurek, 1976; Ryan and Henry, 1979; Leovy and Zurek, 1979], and the general circulation [Pollack et al。, 1976]. Martian weather is much more controlled by topography, surface radiation, and dustiness than is the earth's, although the same basic dynamical processes occur on both planets. The Martian atmosphere thus provides a useful additional means of testing theories of terrestrial meteorology.

Observations of the Martian upper atmosphere indicate a peak election density of $2 \times 10^{5} \mathrm{~cm}^{-3}$ at $110-150 \mathrm{~km}$ altitude, a temperature varying with the solar cycle from $200 \mathrm{~K}$ to $400 \mathrm{~K}$ [Fjeldbo et a1., 1977], and a turbopause at 125 $\mathrm{km}$ altitude [Nier and McElroy, 1977], with $0_{2}{ }^{+}$ the dominant ion [Hanson et al., 1977]. Mars provides a good test of theories of upper atmosphere structure and composition [McE1roy et a1.,
1977].

$$
\text { Jupiter }
$$

Except for a sma11 rocky core, Juptter is thought to be well-mixed and fluid throughout [e.g., Smoluchowsk1, 1976]. Its composition resembles that of the sun and perhaps that of the early solar nebula. Interpretation of remote observations is complicated by the fact that many substances condense out in the clouds, which are thought to extend down to pressures of 5 bars and temperatures of $270 \mathrm{~K}$. Gases that have been detected spectroscopically include $\mathrm{H}_{2}, \mathrm{He}, \mathrm{CH}_{4}$, $\mathrm{NH}_{3}, \mathrm{CH}_{3} \mathrm{D}, \mathrm{H}_{2} \mathrm{O}, \mathrm{PH}_{3}, \mathrm{GeH}_{4}, \mathrm{CO}, \mathrm{C}_{2} \mathrm{H}_{6}$, and $\mathrm{C}_{2} \mathrm{H}_{2}$ [for a review, see Ridgway et al., 1976; see also Hanel et a1., 1979]. The $\mathrm{H} / \mathrm{C} / \mathrm{N}$ ratios are consistent with solar composition. The He/H ratio is also consistent [Orton and Ingersoll, 1976; Hanel et al., 1979] but with a $\pm 30 \%$ fractional uncertainty. The $0 / \mathrm{H}$ ratio is down from the solar value by a factor $\sim 10^{-3}$ [Larson et a1., 1975] but this may be an effect of Jovian meteorology on the $\mathrm{H}_{2} \mathrm{O}$ vapor abundance. Other detected gases are not in chemical equilibrium at the Jovian cloud tops. Their abundances therefore reflect either photochemical effects or effects of rapid mixing from the deep interior [Beer and Taylor, 1978; Barshay and Lewis, 1978]. Some isotopic ratios, particularly D/H and $\mathrm{C}^{13} / \mathrm{C}^{12}$, have been measured, but not with sufficient accuracy to test theories of solar system formation.

Knowledge of the cloud composition and vertical structure (FIg. 4) is inferred from infrared observations [e.g., Orton, 1977; Hanel et al., 1979], radio occultation measurements [K1iore et a1., 1976; Eshleman et al., 1979], photopolarimetry [e.g., Tomasko, 1976], mlcrowave radiometry [KIein and Gulkis, 1978], and chemical equilibrium models [Weidenschilling and Lewis, 1973; Prinn and Owen, 1976; Sill, 1976]. The upper white cloud layer is almost certainly ammonia [Orton, 1975], and sulfur is a good candidate for the brown color of the middle clouds [Sil1, 1976]. Prinn and Lewis [1975] suggest that red phosphor- 


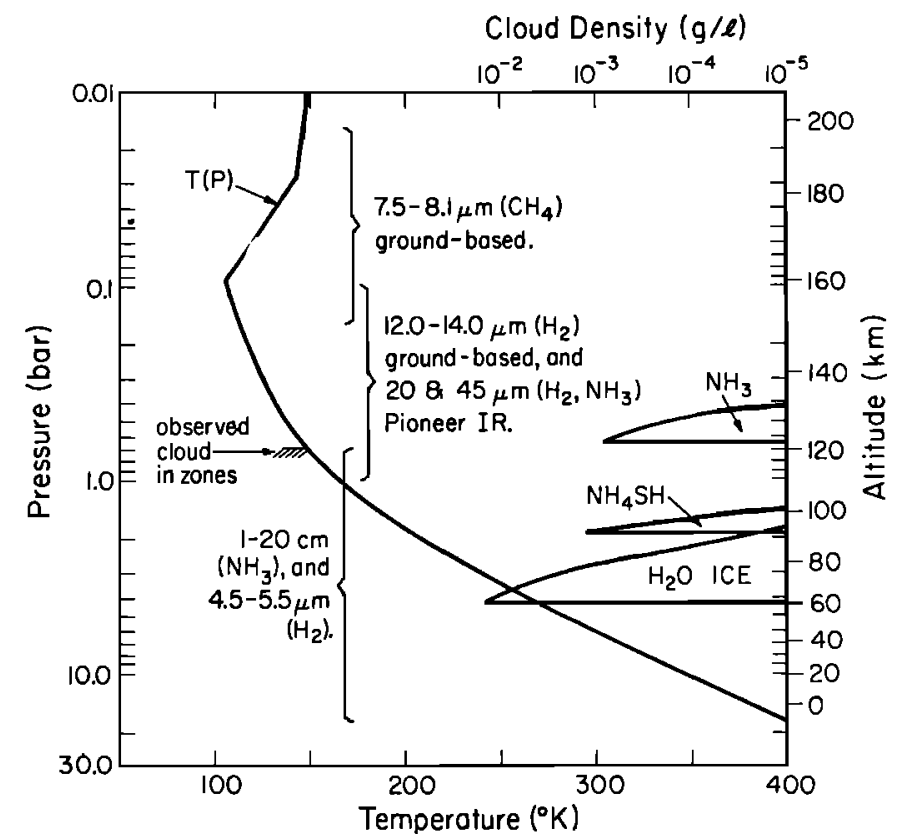

Fig. 4. Vertical structure of Jupiter's atmosphere from $P=0.01$ bar to $P=20$ bar. The zero of altitude is arbitrary. From Ingersol1 (1976). Courtesy of D. Reidel Publishing Company, Inc.

ous provides the color of the Great Red Spot. There is no direct evidence pertaining to the water cloud shown in Fig. 4; its existence is postulated on the basis of elemental abundance ratios only. This picture also lgnores effects of vertical and horizontal transport of cloud constituents and precipitation.

The temperature rise above the 0.1 bar level is presumably due to absorption of sunlight; a stratospheric haze seems necessary to account for the $150 \mathrm{~K}$ temperatures above the $0.01 \mathrm{bar}$ leve1. At higher altitudes ( $P<10^{-7}$ bar), the temperature rises to $1000 \mathrm{~K}$ at $\mathrm{P} \sim 10^{-9} \mathrm{bar}$, where the electron density is $10^{5} \mathrm{~cm}^{-3}$ [Fjeldbo et al., 1975; Eshleman et al., 1979]. Upper atmosphere models [Strobe1, 1975; Atreya and Donahue, 1976] predict much lower $\frac{(\mathrm{T} \sim 150 \mathrm{~K})}{\mathrm{T} \sim 10 \mathrm{~s}}$ temperatures for this region than are observed. Possible energy sources include particles from the Jovian magnetosphere [Broadfoot et al., 1979] and waves fron the lower atmosphere [French and Gierasch, 1974].

The horizontal cloud structure and motions are Inferred from tmaging in the thermal infrared [Ingersoll et al., 1976; Terrile and Westphal, 1977] and visible regions [Gehre1s, 1976; Smith and Hunt, 1976; Reese and Beebe, 1976; Smith et a1。, 1979]. The large-scale $\left(10^{4} \mathrm{~km}\right)$ patterns persist for years or centuries, although circulation times and lifetimes of some small-scale features $\left(10^{2}-10^{3} \mathrm{~km}\right)$ are of ten $a$ few days or less. Voyager Images [Smith et al., 1979] show evidence of sma11-scale convection, gravity waves, instability of zonal jets, planetary turbulence, and other diagnostic processes. Voyager confirmed the Pioneer 10 and 11 observation [Gehrels, 1976] that eastward-propagating equatorial waves receive their energy from smallscale convection. Jovian vortices were observed to combine and Interact in a variety of ways that provide clues about their dynamics. Nevertheless, lack of knowledge of conditions below the cloud tops has resulted in a wide varlety of Jovian general circulation models [Ingersol1, 1976b; Busse, 1976; Maxworthy and Redekopp, 1976;
Williams, 1978; Gierasch, 1976]. These models may be tested by comparing them with the spacetime structures revealed in Voyager images.

Jupiter enits heat at a rate $1.5-2.0$ times that at which it absorbs sunlight [Ingerso11 et a1., 1976]. Models of the cooling history can easily account for this excess [Graboske et al., 1975; Cameron and Pollack, 1976]. The emitted heat $f$ lux is nearly independent of latitude [ Ingersol1 et al., 1976; Hane1 et a1., 1979], which is probably the result of efficient lateral heat transfer in the interior rather than in the visible atmosphere [Ingersoll and Porco, 1978]. Although knowledge of the deep vertical structure will remain limited for years to come, the Voyager mission will help identify those factors that make Jovian meteorology so different from the earth's.

\section{Outer Planets and Satellites}

Jupiter's satellite Io has an ionosphere extending, on the day side, from near the surface to an altitude of at least $700 \mathrm{~km}$, with a peak electron density of $6 \times 10^{4} \mathrm{~cm}^{-3}$ at $100-\mathrm{km}$ altitude. The upper 1imit to the neutral gas pressure at the surface is $10^{-8}$ bar [Kliore et al., 1975]. A torus of singly and doubly ionized sulfur and doubly ionized oxygen in the orbit of Io [Kupo et al., 1976; Broadfoot et al., 1979] and a partial torus of sodium have also been extensively studied [Trafton and Macy, 1978; Bergstra1h et a1., 1975; Brown et a1., 1975; Brown and Young, 1976]. Active volcanos on Io, discovered by Voyager [Morabito et al., 1979; Smith et al., 1979] are clearly the major source of particles. Io's' "atmosphere" may consist largely of volcanic effluents in ballistic trajectories, although a hydrostatic "background" component cannot be ruled out.

Saturn appears to be a less massive version of Jupiter, but with perhaps fewer heavy elements in 1ts outer envelope [Podolak, 1978]. Temperatures are lower, and the pressure at the cloud tops appears to be greater than at Jupiter. 
There have been several models of the thermal structure [Caldwe11, 1977; Tokunaga and Cess, 1977] based on the thermal infrared spectrum [Caldwell et al., 1978]. Saturn, like Jupiter, has a relatively warm stratosphere, perhaps as a result of sunlight absorption by dust [Podolak and Danielson, 1977]. Summer stratospherfic temperatures are expecially warm [Gillett and Orton, 1975], perhaps some $50 \mathrm{~K}$ warmer (130 K vs. $80 \mathrm{~K})$ than the tropopause region [Tokunaga and Cess, 1977; Tokunaga et al., 1978]. Infrared temperatures are higher than predicted for a blackbody, taking into account the effects of the rings, so that Saturn appears to be emitting about twice as much energy as it receives from the Sun [Ward, 1977; Erlckson et al., 1978].

Saturn's satellite Titan has a significant neutral atmosphere of methane and possibly other gasses [Hunten, 1977; Danehy et a1., 1978]. Nitrogen may comprise the dominant species, possibly having been formed photochemically from ammonia early in the planet's history [Atreya et a1., 1978]. Theories of the thermal structure postulate either a strong inversion layer in the stratosphere [Podolak and Danielson, 1977] or else a strong greenhouse effect [Pollack, 1973].

Uranus has a deep hydrogen-methane atmosphere [Danielson, 1977; Gulkis et al., 1978; Hubbard, 1975; Trafton, 1976]. Its period of rotation is in the range 10-20 hours [Hayes and Belton, 1977; Trafton, 1977; Trauger et al., 1978; Brown and Goody, 1977]. Circulation patterns, If they were observable from earth, would be of considerable theoretical interest because of the planet's near $-90^{\circ}$ obliquity [Stone, 1977]. Neptune's atmosphere is of similar bulk composition to that of Uranus [e.g., Hunt, 1978], although there are observable differences in at least one minor constituent [Macy and Sinton, 1977]. Both appear to have strong inversion layers in the upper atmosphere [Gillett and Rieke, 1977; Macy and Trafton, 1975] which may result from absorption of sunlight by methane [Wallace, 1975; Macy and Trafton, 1975]. Infrared observations yield a brightness temperature for Neptune about $10 \mathrm{~K}$ greater than the blackbody temperature, possibly indicating the presence of an internal heat source [Loewenstein et a1., 1977a]. Relatively short-lived brightenings of Neptune in the nearinfrared reflectance may be due to changes in the cloud cover [Joyce et al., 1977; Pilcher, 1977]. There are reports of a secular increase in the brightnesses of Saturn, Titan and Neptune since 1972 [Lockwood, 1977, 1978], which may reflect slow changes of albedo for all of these objects.

Acknowledgments. This research was partially supported by NASA Grant NGL 05-002-003.

\section{References}

Ainsworth, J.E., and J.R. Herman, On the reality of the Venus winds, Icarus, 30, 314-319, 1977.

Ainsworth, J.E., and J.R. Herman, An analysis of the Venus thermal infrared temperature maps, J. Geophys. Res., 83, 3113-3124, 1978.

Anders, E, and T. Owen, Mars and Earth: Origin and abundance of volat1les, Science, 198, 453-465, 1977.

Anderson, E., and C. Leovy, Mariner 9 television limb observations of dust and ice hazes on Mars, J. Atmos. Sci., 35, 723-734, 1978.

Anderson, J.L., M.J.S. Belton, G.E. Danielson, N. Evans, and J.M. Soha, Venus in motion.

Astrophys. J. Supp. Series, 36, 275-284, 1978.

Antsibor, N.M., R.V. Bakit'ko, A.L. Ginzburg. V.T. Guslyakov, V.V. Korzhanovich, Yu. F. Makarov, M. Ya . Marov, E.P. Mulutov, V.I. Rogal'ski1, M.K. Rozhdestrenskii, V.P. Supukin, and Yu. N. Shaygin, Estimates of wind velocity and turbulence from relayed doppler measurements of the velocity of instruments dropped from Venera 9 and Venera 10, Cosmic Research, 14, 625-632, 1976.

Atreya, S.K., and T.M. Donahue, Ionospheric models of Saturn, Uranus, and Neptune, Icarus, 24, $358-362,1975$.

Atreya, S.K., and T.M. Donahue, The role of hydrocarbons in the ionospheres of the outer planets, Icarus, 25, 335-338, 1975.

Atreya, $S_{.} \bar{K}_{\bullet}$, and T.M. Donahue, Model ionospheres of Jupiter, in Jupiter, edited by T. Gehrels, pp. 304-318, University of Arizona Press, Tucson, 1976.

Atreya, S.K., T.M. Donahue, and W.R. Kuhn, The distribution of ammonia and its photochemical products on Jupiter, Icarus, 31, 348-355, 1977.

Atreya, S.K., T.M. Donahue, and W.R. Kuhn, Evolution of a nitrogen atmosphere on Titan, Science, 201, 611-613, 1978 .

Aumann, H.H., and G.S. Orton, Jupiter's spectrum between 12 and 24 micrometers, Science, 194, 107-109, 1976.

Avduevski1, V.S., N.F. Borodin, V.P. Burtsev, Ya. V. Malkov, M.Ya Marov, S.F. Morozov, M.K. Rozhdestvenski1, R.S. Romanov, S.S. Sokolov, V.G. Fokin, Z.P. Chevemukhina, and V.I. Shkirina, Automatic stations Venera 9 and Venera 10 -Functioning of descent vehtcles and measurement of atmospheric parameters, Cosmic Research, 14, $577-586,1976 a$.

Avduevskii, V.S., S.L。Vishevetskii, I.A. Golov, Yu.Ya. Karpe1skil, A.D. Lavrov, V.Ya. Likhushin, M.Ya. Marov, D.A. Mel'nikov, N.I. Pomogin, N.N. Pronina, K.A. Razin, and V.G. Fokin, Measurement of wind velocity on the surface of Venus during the operation of stations Venera 9 and Venera 10, Cosmic Research, 14, 622-625, 1976b. Avduevski1, V.S., Yu.M. Golovin, F.S. Zavelevich, V.Ya. Likhushin, M.Ya, Marov, D.A. Mel'ntkov, Ya.I. Merson, B.E. Moshkin, K.A. Razin, L.I. Chernoshchekov, and A.P. Ekonomov, Preliminary results of an investigation of the lighting conditions in the atmosphere and on the surface of Venus, Cosmic Research, 14, 643-649, $1976 \mathrm{c}$.

Baker, A.L., L.R. Baker, E. Beshore, C. Blenman, N.D. Castillo, Y-P. Chen, L.R. Doose, J.P. Elston, J.W. Fountain, T. Gehrels, J.H. Kendall, C.E. Kenknight, R.A. Norden, W. Swinde11, M.G. Tomasko, and D.L. Coffeen, The imaging photopolarimeter experiment on Pioneer 11, Science, $188,468-472,1975$.

Barshay, S.S., and J.S. Lewis, Chemistry of primItive solar material, Ann. Rev. of Astron. and Astrophys., 14, 81-94, 1976 .

Barshay, S.S., and J.S. Lewis, Chemical structure of the deep atmosphere of Jupiter, Icarus, 33 , 593-611, 1978.

Bauer, S.J., L.H. Brace, D.M. Hunten, D.S. Intrilligator, W.C. Knudsen, A.F. Nagy, C.T. Russe11, F.L. Scarf, and J.H. Wolfe, The Venus ionosphere and solar wind Interaction, Space 
Sci. Rev., 20, 413-430, 1977.

Beer, R., Jupiter and the boron problem, Icarus, 29, 193-200, 1976.

Beer, R., and F.W. Taylor, The $\mathrm{D} / \mathrm{H}$ and $\mathrm{C} / \mathrm{H}$ ratios in Jupiter from the $\mathrm{CH}_{3} \mathrm{D}$ phase, Astrophys. J., 219, 763-767, 1978.

Beer, R., and R.W. Taylor, The abundance of carbon monoxide in Jupiter, Astrophys. J., 221, 1100$1109,1978$.

Belton, M.J.S., and S.H. Hayes, An estimate of the temperature and abundance of $\mathrm{CH}_{4}$ and other molecules in the atmosphere of Uranus, Icarus, 24, 348-357, 1975.

Bellton, M.J.S., and F.E. Vescelus, Why image Uranus? Icarus, 24, 299-310, 1975.

Belton, M.J., G.R. Smith, D.A. Elliott, K. Klaasen, and G.E. Danielson, Space-time relationships in the UV markings on Venus, J. Atmos. Sci., 33, 1383-1393, 1976 。

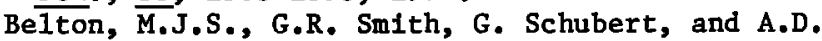
Del Genlo, Cloud patterns, waves, and convection in the Venus atmosphere, J. Atmos. Sc1., 33, 1394-1417, 1976.

Benner, D.C., U. Fink, and R.H. Cromwell, Image tube specta of Pluto and Triton from 6800 to $9000 \AA$, Icarus, $36,82-91,1978$.

Bergstra1h, J.T., D.L. Matson, T.V. Johnson, Sodium D-1ine emission from Io: Synoptic observations from Table Mountain Observatory, Astrophys. J., 195, L131-L135, 1975.

Bernatowicz, T., and F.A. Podosek, Nuclear components in the atmosphere, in Terrestrial Rare Gases, edited by E.C. Alexander, Jr., and M. Ozima, pp. 99-135, Japan Scientific Societies Press, Tokyo, 1978.

Bertaux, J.L., J.E. Blamont, A.I. Dzyubenko, V.G. Kurt, T.A. Mizyakina, E.N. Mironova, N.N. Romanova, and A.S. Smirnov, Investigation of scattered $L_{\alpha}$ radiation in the vicinity of Venus, Cosmic Research, 14, 695-701, 1976.

Betz, A.L., R.A. McLaren, E.C. Sutton, and M.A. Johnson, Infrared heterodyne spectroscopy of $\mathrm{CO}_{2}$ in the atmosphere of Mars, Icarus, 30, 650$662,1977$.

Blemann, K., T. Owen, D.R. Rushneck, A.L. LaFleur, and D.W. Howarth, The atmosphere of Mars near the surface: Isotope ratios and upper limits on noble gases, Science, 194, 76-78, 1976.

Biemann, K., J. Oro, P. Toulmin, III, L.E。 Orgel, A.0. Nier, D.M. Anderson, P.G. Simmonds, D. Flory, A.V. Diaz, D.R. Rushneck, J.E. Biller, and A.L. LaFleur, The search for organic substances and inorganic volatile compounds in the surface of Mars, J. Geophys. Res., 82, 4641$4658,1977$.

Biols1, L., Transport properties in the Jovian atmosphere, J. Geophys. Res., 83, 1125-1131, 1978.

Booth, M.C., and H.H. Kieffer, Carbonate formation In Marslike environments, J. Geophys. Res., 83, 1809-1815, 1977.

Briggs, G., K. Klaasen, T. Thorpe, J. Wellman, and $W$. Baum, Martian dynamical phenomena during June-November 1976: Viking Orbiter Imaging results, J. Geophys. Res., 82, 4121-4150, 1977.

Broadfoot, A.L., M.J.S. Bel ton, B.R. Sande1, D.E. Shemansky, P.Z. Takacs, J.B. Holberg, J.M. Ajello, S.K. Atreya, T.M. Donahue, H.W. Moos, J.L. Bertaux, J,E, Blamont, D.F, Strobel, J.C. McConnell, A. Dalgarno, R. Goody, and M.B. McElroy, Extreme ultraviolet observations from
Voyager 1 encounter with Jupiter, Science, 204 979-982, 1979.

Broadfoot, A.L., D.E. Shemansky, and S. Kumar, Mariner 10: Mercury atmosphere, Geophys。 Res. Lett., 3, 577-580, 1976.

Brown, R. $\vec{A}_{0}$, and R.M. Goody, The rotation of Uranus, Astrophys. J., 217, 680-687, 1977.

Brown, R.A., and R.M. Goody, The persistence and size of thermal anomalles on Venus, Icarus, 35, 189-195, 1978.

Brown, R.A., and Y.L. Yung, Io, its atmosphere and optical emissions, in Jupiter, edited by T. Gehrels, pp. 1102-1145, U. of Arizona Press, 1976.

Brown, R.A., R.M. Goody, F.J. Murcray, F.H. Chaffee, Further studies of 1ine emission from Io, Astophys. J., 200, L49-I53,1975.

Browne, G.C., and A.J. Meadows, Light and dark spots in the equatorial regions of Jupiter, Planet. Space Sc1., 26, 335-338, 1978.

Busse, F.H., A simple model of convection in the Jovian atmosphere, Icarus, 29, 255-260, 1976.

Caldwell, J., The atmosphere of Saturn: An Infrared perspective, Icarus, 30, 493-510, 1977.

Caldwell, J., F.C. Gillett, I.G. Nolt, and A. Tokunaga, Spatially resolved infrared observations of Saturn. I. Equatorial limb scans at 20 $\lrcorner \mathrm{m}$, Icarus, 35, 308-312, 1978.

Cameron, A.G.W., The origin and evolution of the solar system, Scientific American, 233(3), $32-41,1975$.

Cameron, A.G.W., and J.B. Pollack, On the origin of the solar system and of Jupiter and its satellites, in Jupiter, edited by T. Gehrels, pp. 61-84, University of Arizona Press, Tucson, 1976.

Capone, L.A., R.C. Whitten, J. Dubach, S.S. Prasad, and W.T. Huntress, Jr., The lower lonosphere of Titan, Icarus, 28, 367-378, 1976.

Capone, L.A., R.C. Whitten, S.S. Prasad, and J. Dubach, The lonospheres of Saturn, Uranus, and Neptune, Astrophys. J., 215, 977-983, 1977.

Carlson, R.W., and D.L. Judge, Ploneer $10 \mathrm{UV}$ photometer observations of the Jovian hydrogen torus: The angular distribution, Icarus, 24, 395-399, 1975.

Cess, R.D., and S.C. Chen, The Influence of ethane and acetylene upon the thermal structure of the Jovian atmosphere, Icarus, 26, 444-450, 1975.

Chalikov, D.V., A.S. Monin, A.S. Safray, V.G. Turikov, and S.S. Zilitinkevich, Numerical simulation of the general circulation of the Cytherean lower atmosphere, Icarus, 26, 178-208, 1975.

Conrath, B.J., Thermal structure of the Martian atmosphere during the dissipation of the dust storm of 1971, Icarus, 24, 36-46, 1975.

Crisp, D., and A.T. Young, Vertical extent of zonal winds on Venus, Icarus, 35, 182-188, 1978.

Crump. P.C., R.M. Kellerman, and D.P. Cruikshank, The rotation and morphology of small red spots on Jupiter in 1974, Icarus, 29, 221-224, 1976.

Danehy, R.G., T. Owen, B.L. Lutz, and J.H. Woodman, Detecting of the Kuiper bands in the spectrum of Titan, Icarus, 35, 247-251, 1978.

Danielson, R.E., The structure of the atmosphere of Uranus, Icarus, 30, 462-478, 1977.

Danielson, R.E., W.D. Cochran, P.G. Wannier, and E.S. Light, A saturation mode1 of the atmosphere of Uranus, Icarus, 31, 97-109, 1977. 
Davies, D.W., C.B. Farmer, and D.D. LaPorte, Behavior of volatiles in Mars' polar areas: A model incorporating new experimental data, J. Geophys. Res., 82, 3815-3822, 1977.

de $\bar{R}$ ivas, E.K., Further numerical calculations of the circulation of the atmosphere of Venus, J. Atmos. Sc1., 32, 1017-1024, 1975.

Devaux, $C$, and $M_{0}$ Herman, Venus: Cloud optical depth and surface albedo from Venera 8, Icarus, 24, 19-27, 1975.

Dickel, J.R., The microwave spectrum of ammonia in Jupiter's atmosphere, Icarus, 29, 283-286, 1976.

Dickinson, R.E., and E.C. Ridley, A numerical model for the dynamics and composition of the Venusian thermosphere, J. Atmos. Sci., 32, 1219-1231, 1975.

Dicktnson, R.E., and E.C. Ridley, Venus mesosphere and thermosphere temperature structure. II. Daynight variations, Icarus, 30, 163-178, 1977.

Diner, DoJ., and J.A. Westpha1, Silicon vidicon imaging of Jupiter. 4100 - to $8300-\AA$ absolute reflections and limb darkening of spatially resolved regions, Icarus, 32, 299-313, 1977.

Diner, D.J., J.A. Westpha1, and F.P. Schloerb, Infrared Imaging of Venus: 8-14 micrometers, Icarus, 27, 191-196, 1976.

Diner, D.J., and J.A. Westpha1, Phase coverage of Venus during the 1975 apparition. Diurnal variations in equatorial infrared brightness, Icarus, 36, 119-126, 1978。

Dobrovolskis, A. and A.P. Ingersoll, Carbon Dioxide--Water cathrate as a reservoir of $\mathrm{CO}_{2}$ on Mars, Icarus, 26, 353-357, 1975.

Dollfus, A., H. Camichel, C. Boyer, M. Auriere, E. Bowell, and J. Nikander, Photometry of Venus. I. Observation of the brightness distribution over the d1sk, Icarus, 26, 53-72, 1975 .

Dzurisin, D., and A.P. Ingersoll, Seasonal buffering of atmospheric pressure on Mars, Icarus, 26, 437-440, 1975.

El11ot, J.L., R.G. French, E. Dunham, P.J. Glerasch, J. Veverka, C. Church, and C. Sagan, Occultation of $\epsilon$ Geminorum by Mars: Evidence for atmospheric tides? Science, 195, 485-486, 1977.

Erickson, E.F., D. Goorvitch, J.P. Simpson, and D.W. Strecker, Far infrared spectrophotometry of Jupiter and Saturn, Icarus, 35, 61-73, 1978 .

Eshleman, V.R., G.L. Tayler, G.E. Wood, G.F. Lindal, J.D. Anderson, G.S。Levy, and T.A. Croft, Radio science with Voyager 1 at Jupiter; Preliminary profiles of the atmosphere and lonosphere, Sclence, 204, 977-978, 1979.

Fanale, F.P., Martian volatiles: Their degassing history and geochemical fate, Icarus, 28, 179-202, 1976.

Fanale, F.P., and $W_{\circ} A$. Cannon, Mars: The role of the regolith in determining atmospheric pressure and the atmosphere's response to insolation changes, J. Geophys。 Res., 83, 2321-2325, 1978.

Fanale, F.P., W.A. Cannon, and T. Owen, Mars: Regolith adsorption and the relative concentrations of atmospheric rare gases, Geophys. Res. Lett., 5, 77-80, 1978.

Fanale, F.P., T.V. Johnson, and D.L. Matson, Io's surface composition: Observational constraints and theoretical considerations, Geophys. Res. Lett., 4, 303-306, 1977.

Farmer, C.B., Liquid water on Mars, Icarus, 28,
279-290, 1976.

Farmer, C.B., D.W. Davies, A.L. Holland, D.D. LaPorte, and P.E. Doms, Mars: Water vapor observations from the Viking orbiters, J. Geophys. Res., 82, 4225-4248, 1977.

Farmer, C.B., D.W. Davies, and D。D. LaPorte, Mars: Northern summer 1ce cap-water vapor observations from Viking 2, Science, 194, 1339-1341, 1976.

Fazio, G.G., W.A. Traub, and E.L. Wright, The effective temperature of Uranus. Astrophys. J. $209,633-637,1976$.

Ferris, J.P., and C.T. Chen, Photosynthesis of organic compounds in the atmosphere of Jupiter, Nature, 258, 587-588, 1975.

Fink, U., H.P. Larson, and R.R. Treffers, Germane in the atmosphere of Jupiter, Icarus, 34, 344$354,1978$.

Fink, U., H.P. Larson, and T.N. Gautier, III, New upper limits for atmospheric constituents on Io, Icarus, 27, 439-446, 1976.

Fink, U., and H.P. Larson, Deuterated methane observed on Saturn, Sclence, 201, 343-345, 1978.

Fisher, D.E., Rare gase clues to the origin of the terrestrial atmosphere, in The Early History of the Earth, edited by B.F. Windley, PP. 547-556, Wiley, London, 1976.

Fjeldbo, G., B. Seldel, D. Sweetnam, and T. Howard, The Mariner 10 radio occultation measurements of the ionosphere of Venus, J. Atmos. Sci., 32, 1232-1236, 1975.

Fjeldbo, G., A. Kliore, D. Sweetnam, P. Fsposito, B. Seidel, and T. Howard, The occultation of Mariner 10 by Mercury, Icarus, 29, 439-444, 1976.

Fjeldbo, G., D. Sweetnam, J. Brenkle, E. Christensen, D. Farless, J. Mehta, B. Seldel, W. Michael, Jr., A. Wallio, and M. Grossi, Viking radio occultation measurements of the Martian atmosphere and topography: Primary mission coverage, J. Geophys. Res., 82, 43174324, 1977.

Florensky, C.P., V.P. Volkov, O.V. Nikolaeva, A geochemical model of the Venus troposphere, Icarus, 33, 537-553, 1978.

French, R., and $P_{0}$ Gierasch, Waves in the Jovian upper atmosphere, J. Atmos. Sc1., 31, 1707$1712,1974$.

Furniss, I., R.E. Jennings, and K.J, King, Observations of the far infrared spectrum of Jupiter, Icarus, 35, 74-78, 1978.

Gehrels, T., The two types of atmosphere of Jupiter and Saturn, in Chemical Evolution of the Giant Planets, edited by C. Ponnamperuma ppo 1-11, Academic Press, New York, 1976.

Gehrels, T., The results of the imaging photopolarimeter on Pioneers 10 and 11, in Jupiter, edited by T. Gehrels, pp. 531-563, U. of Arizona Press, 1976.

Gierasch, P.J., Meridional circulation and the maintenance of the Venus atmospheric rotation, J. Atmos. Sci., 32, 1038-1044, 1975.

Gierasch, P.J., Jovian meteorology: Large-scale moist convection, Icarus, 29, 445-454, 1976.

Gillett, F.C., and G.S. Orton, Center-to-1imb observations of Saturn in the thermal infrared, Astrophys. J., 195, L47-L49, 1975.

Gillett, F.C., and G.H. Rieke, 5-20 micron observations of Uranus and Neptune, Astrophys. $\mathrm{J}_{0}$, 218, L141-L144, 1977.

Goepel, J., B. Nicholson, and J.A. Ryan, 
Discrete events at Viking-2 Mars site, northern summer, Geophys. Res. Lett., 5, 949-951, 1978.

Goorvitch, D., The ammonia mixing ratio in Jupiter's stratosphere, Icarus, 36, 127-132, 1978.

Graboske, H.C., J.B. Pollack, A.S. Grossman, and R.J. Olness, The structure and evolution of Jupiter: The fluid contraction stage, Astrophys. J., 199, 265-281, 1975.

Gross, S.H., and G.V. Ramanathan, The atmosphere of Io, Icarus, 29, 493-508, 1976.

Gulkis, S., R.K. Kakar, M.J. Klein, E.T. O1sen, and W.J. Wilson, Venus: Detection of variations in stratospheric carbon monoxide, in Proceedings Symposium on Planetary Atmospheres, edited by $A . V$. Jones, pp. 61-66, Herzberg Institute, Ottawa, Canada, 1977.

Gulkis, S., M.A. Janssen, and E.T. Olsen, Evidence for the depletion of ammonia in the Uranus atmosphere, Icarus, 34, 10-19, 1978.

Hamano, Y., and M. Ozima, Earth-atmosphere evolution model based on Ar 1sotopic data, in Terrestrial Rare Gases, edited by E.C. Alexander, Jr., and M. 0zima, pp. 155-171, Japan Scientific Societies Press, Tokyo, 1978.

Hanel, R.A., Exploration of the glant planets by infrared spectroscopy, in Chemical Evolution of the Giant Planets, edited by C. Ponnamperuma, Pp. 165-182, Academic Press, New York, 1976.

Hane1, R., B. Conrath, M. Flasar, V. Kunde, P. Lownan, W. Maguire, J. Pearl, J. Pirraglia, R. Samuelson, D. Gautier, P. Glerasch, S. Kumar, and C. Ponnamperuma, Inf rared observations of the Jovian system from Voyager 1, Science, 204, 972-976, 1979.

Hanson, W.B., S. Sanatani, and D.R. Zuccaro, The Martian Ionosphere as observed by the Viking retarding potential analyzers, J. Geophys. Res. 82, 4351-4363, 1977.

Hapke, B., The phase function of Venus cloud particles from Mariner 10 data, Geophys. Res. Lett., 5, 1067-1070, 1978.

Hapke, B., and R. Nelson, Evidence for an elemental sulfer component of the clouds from Venus spectrophotometry, J. Atmos. Sci., 32, 1212-1218, 1975.

Hartle, R.E., S.A. Curtis, and G.E. Thomas, Mercury's hellum exosphere, J. Geophys. Res., 80, 3689-3692, 1975.

Hartmann, W.K., Mars: Topographic control of clouds, 1907-1973, Icarus, 33, 380-387, 1978.

Hayes, S.H., and M.J.S. Belton, The rotational periods of Uranus and Neptune, Icarus, 32, 383-401. 1977 .

Hess, S.L., R.M. Henry, C.B. Leovy, J.A. Ryan, J.E. Tillman, T.E. Chamberlain, H.I. Cole, R.G. Dutton, G.C. Greene, W.E. Simon, and J.L. Mitche11, Preliminary meteorological results from the Viking-1 lander, Science, 193, 788$790,1976$.

Hess, S.L., R.M. Henry, C.B. Leovy, J.A. Ryan, and J.E. Tillman, Meteorological results from the surface of Mars: Viking-1 and 2, J. Geophys. Res., 82, 4559-4574, 1977.

Hoffman, J.H., R.R. Hodges, Jr., M.B. McElroy, T.M. Donahue, and M. Kolpin, Venus lower atmospheric composttion - Preliminary results from Pioneer Venus, Science, 203, 800-802, 1979.

Hogan, J.S., R.D. Cess, T. Encrenaz, and D. Gautier, Jupiter: Interpretation of the Pioneer 10 infrared radiometer and S-band occultation observations. I. Atmos. Sc1., 32, 860-862, 1975.

Houben, H., and P.J. Gierasch, Jupiter's tidal $Q$ due to atmospheric tides, in Proceedings Symposium on Planetary Atmospheres, edited by A.V. Jones, pp. 79-84, Herzberg Institute, Ottawa, Canada, 1977.

Houck, J.R., J.B. Pollack, D. Schaack, R.A. Reed, and A. Summers, Jupiter: Its infrared spectrum from 16 to 40 micrometers, Science, 189, 720$722,1975$.

Hubbard, W.B., Interior structure of Uranus, Icarus, 24, 285-291, 1975.

Hubbard, W.B., The Jovian surface condition and cooling rate, Icarus, 30, 305-310, 1977.

Hubbard, W.B., D.M. Hunten, and A. Kllore, Effect of the Jovian oblateness on Ploneer 10/11 radio occultations, Geophys. Res. Lett. 2, 265-268, 1975.

Huguenin, R.L., Mars: Chemical weathering as a massive volatile sink, Icarus, 28, 203-212, 1976.

Huguenin, R.L., R.G. Prinn, and M. Maderazzo, Mars: Photodesorption from mineral surfaces and 1 ts effects on atmospheric stability, Icarus, 32, 270-298, 1977.

Hunt, G.E., Atmospheres of Uranus and Neptune, Nature, 272, 403-404. 1978.

Hunt, G.E., and P.B. James, Martian extratropical cyclones, Nature, 278, 531-532, 1979.

Hunten, D.M., The outer planets, Scientific American, 233(3), 130-141, 1975.

Hunten, D.M., Titan's atmosphere and surface, in Planetary Satellites, edited by J.A. Burns, Pp. 420-437, University of Arizona Press, Tucson, 1977.

Hunten, D.M., and T.M. Donahue, Hydrogen loss from the terrestrial planets. Ann. Rev. Earth Planet. Sci. 4, 265-292, 1976.

Ingersol1, A.P., The atmosphere of Jupiter, Space Sci. Rev., 18, 603-640, 1976a.

Ingerso $\overline{11}$ A.P., Pioneer 10 and 11 observations and the dynamics of Jupiter's atmosphere, Icarus, 29, 245-254, 1976b.

Ingersol1, A.P., and A.R. Dobrovolskis, Venus' rotation and atmospheric tides, Nature, 275, $37-38,1978$

Ingersol1, A.P., and C.C. Porco, Solar heating and 1nternal heat flow on Jupiter, Icarus, 35, $27-43,1978$.

Ingerso11, A.P., G. Minch, G. Neugebauer, D.J. Diner, G.S. Orton, B. Schupler, M. Schroeder, S.C. Chase, R.D. Ruiz, and L.M.Trafton, Pioneer 11 infrared radiometer experiment: The global heat balance of Jupiter, Science, 188, 472-473, 1975.

Ingerso11, A.P., G. Mtinch, G. Neugebauer, and G.S. Orton, Results of the infrared radiometer experiment on Pioneers 10 and 11 , in Jupiter, edited by T. Gehrels, pp. 197-205, University of Arizona Press, 1976.

Iversen, J.D., R. Greeley, and J.B. Pollack, Windblown dust on Earth, Mars, and Venus, J. Atmos. Sci., 33, 2425-2429, 1976.

Izakov, M.N., The martian upper atmosphere structure from the Viking spacecraft experiments, Icarus, 36, 189-197, 1978.

James, P.B., G. Briggs, J. Barnes, A. Spruck, Seasonal recession of Mars' south polar cap as seen by Viking, J. Geophys, Res., 84, 28892922, 1979. 
Jokipif, J.R., and W.B. Hubbard, Stellar occu1tations by turbulent palentary atmospheres: The Beta Scorpii events, Icarus, 30, 537-550, 1977.

Joyce, R.R., C.B. Pilcher, D.P. Cruikshank, and D. Morrison, Evidence for weather on Neptune. $I$. Astrophys. J., 214, 657-662, 1977.

Kakar, R.K., J.W. Waters, and W.J. Wilson, Venus: Microwave detection of carbon monoxide, Science, $191,379-380,1976$.

Kawabata, K., and J.E. Hansen, Interpretation of the variation of polarization over the disk of Venus, J. Atmos. Sc1., 32, 1133-1139, 1975.

Keating, G.M., R.H. Tolson, and E.W. Hinson, Venus thermosphere and exosphere: First satellite drag measurements of an extraterrestrial atmosphere, Science, 203, 772-774, 1979.

Keldysh, M.V., Venus expolaration with the Venera 9 and Venera 10 spacecraft, Icarus, 30, 605$625,1977$.

Kemp, J.C., R.J. Rudy, M.J. Lebofsky, and G.H. Rieke, Near-infrared polarization studies of Saturn and Jupiter, Icarus, 35, 263-271, 1978.

Kerzhanovich, W.V., and M.Y. Marov, on the windvelocity measurements from Venera spacecraft data, Icarus, 30, 320-325, 1977.

Kleffer, H.H., S.C. Chase, Jr., T.Z. Martin, E.D. Miner, and F.D. Palluconi, Martian north pole summer temperatures: Dirty water ice, Science, 194, 1341-1344, 1976a.

Kieffer, H.H., P。R. Christensen, T.Z. Martin, E.D. Miner, and F.D. Palluconi, Temperatures of the Martian surface and atmosphere: Viking observations of diurnal and geometric variations, Science, 194, 1346-1351, 1976b.

Kieffer, H.H., T.Z. Martin, A.R. Peterfreund, B.M. Jakosky, E.D. Miner, and F.D. Palluconl, Thermal and albedo mapping of Mars during the Viking Primary Mission, J. Geophys, Res., 르, 4249-4291, 1977.

Klein, MoJ。, and S。 Gulkis, Jupiter's atmosphere: Observations and interpretations of the microwave spectrum near $1,25-\mathrm{cm}$ wavelength, Icarus, $35,44-60,1978$.

Kliore, A.J., and P.M. Woiceshyn, Structure of the atmosphere of Jupiter from Pioneer 10 and 11 radio occultation measurements, in Jupiter, edited by T. Gehrels, pp.216-237, University of Arizona Press, 1976.

Kliore, A.J., G. Fjeldbo, B.L. Seide1, D.N. Sweetnam, T.T. Sesplaukis, P.M. Wolceshyn, and S.I. Rasool, The atmosphere of Io from Pioneer 10 radio occultation measurements, Icarus, 24, 407-410, 1975 .

Kliore, A.J., P.M. Wolceshyn, and W.B. Hubbard, Temperature of the atmosphere of Jupiter from Pioneer 10/11 radio occultations, Geophys. Res. Lett. , 3, 113-116, 1976.

Knacke, R.F., T. Owen, and R.R. Joyce, Inf rared observations of the surface and atmosphere of Titan, Icarus, 24, 460-464, 1975.

Knollenberg, R.G., and D.M. Hunten, Clouds of Venus: Particle size distribution measurements, Science, 203, 792-795, 1979.

Kong, T.Y., and M.B. McElroy, The global distribution of $\mathrm{O}_{3}$ on Mars, P1anet. Space Sci., 25, $839-857,1977 \mathrm{a}$.

Kong, T.Y., and M.B. McElroy, Photochemistry of the Martian atmosphere, Icarus, 32, 168-189, $1977 \mathrm{~b}$.

Krasnopolsky, V.Ao, On the structure of Mars' atmosphere at 120-220 km, Icarus, 24, 28-35, 1975.

Krasnopol'skii, V.A., A.A. Krys'ko, V.N. Rogachev, and V.A. Parshev, Spectroscopy of the nightsky luminescence of Venus from the interplanetary spacecraft Venera 9 and 10, Cosmic Research, 14, 687-692, 1976.

Ksanfomaliti, L.V., E.V. Dedova, L.F. Obykhova, N.V. Terhaya, and G.F. Filippov, Infrared radiation of the clouds of Venus, Cosmic Research, 14, 670-677, 1976.

Kumar, S., Mercury's atmosphere: A perspective after Mariner 10, Icarus, 28, 579-592, 1976.

Kupo, I., Yu. Mekler, and A. Eviatar, Detection of ionized sulfur in the Jovian magnetosphere, Astrophys. J., 205, L51, 1976.

Lacis, A.A., Cloud structure and heating rates in the atmosphere of Venus, J. Atmos. Sci., 32, $1107-1124,1975$.

Larson, H.P., U. Fink, R. Treffers, and T.N. Gautier, Detection of water vapor on Jupiter, Astrophys. J., 197, L137-L140, 1975.

Larson, H.P., U. Fink, and R.R. Treffers, Evidence for CO in Jupiter's atmosphere. Astrophys. J., 219, 1084-1092, 1978.

Lecacheux, J., C. deBergh, M. Combes, and J.P. Maillard, The $\mathrm{C} / \mathrm{H}$ and $12 \mathrm{CH}_{4} / 13 \mathrm{CH}_{4}$ ratios in the atmospheres of Jupiter and Saturn from $0.1 \mathrm{~cm}^{-1}$ resolution near infrared spectra, Astron. Astrophys. , 53, 29-33, 1976.

Leighton, R. B., and B.C. Murray, Behavior of carbon dioxide and other volatiles on Mars, Science, 153, 136-144, 1966.

Leovy, C.B., The atmosphere of Mars, Scientific American, 237 (1), 34-43, 1977.

Leovy, C.B., and R.W. Zurek, Thernal tides and Martian dust storms: Direct evidence for coupling, J. Geophys. Res., 84, 2956-2968, 1979.

Levine, J.S., The evolution of $\mathrm{H}_{2} \mathrm{O}$ and $\mathrm{CO}_{2}$ on Earth and Mars, in Comparative Planetology, edited by C. Ponnamperuma, pp. 165-182, Academic Press, New York, 1978.

Lewis, J.S., Equilibrium and disequilibrium chemistry of adiabatic, solar-composition planetary atmospheres, in Chemical Evolution of the Glant Planets, edited by C. Ponnamperuma, PP. 13-25, Academic Press, New York, 1976.

Limaye, S., and U. Suomi, A normalized view of Venus, J. Atmos. Sci。, 34, 205-215, 1977.

Liu, S.C., and T.M. Donahue, The aeronomy of the upper atmosphere of Venus, Icarus, 24, 148-156, 1975.

Liu, S.C., and T.M. Donahue, The regulation of hydrogen and oxygen escape from Mars, Icarus, 28, 231-246, 1976.

Lockwood, G.W., Secular brightness increases of Titan, Uranus, and Neptune, 1972-1976, Icarus, 32, 413-430, 1977.

Lockwood, G.W., Analysis of photometric variations of Uranus and Neptune since 1953, Icarus, $35,79-92,1978$ 。

Loewenstein, R.F., D.A. Harper, and H. Moseley, The effective temperature of Neptune, Astrophys. J., 218, L145-L146, 1977.

Loewenstein, R.F., D.A. Harper, S.H. Moseley, C.M. Telesco, R. Winston, and R.F. Stiening, FarInfrared and submillimeter observations of the planets, Icarus, 31, 315-324, 1977.

Macy, W., Inhomogeneous models of the atmosphere of Saturn, Icarus, 32, 328-347, 1977.

Macy, W., Jr., J. Gelfand, and W.H. Smith, Inter- 
pretation of the $6818.9 \AA$ methane line in terms of inhomogeneous scattering models for Uranus and Neptune, Icarus, 34, 20-27, 1978.

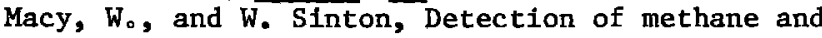
ethane emission on Neptune, but not on Uranus, Astrophys. J., 218, L79-L81, 1977.

Macy, $W_{0}, J r .$, and $W_{. H}$. Smith, Detection of $\mathrm{HD}$ on Saturn and Uranus, and the $\mathrm{D} / \mathrm{H}$ ratio, Astrophys. J., 222, L73-L75, 1978.

Macy, W., and L.Trafton, Neptune's atmosphere: The source of the thermal inversion, Icarus, $26,428-436,1975$.

Maguire, W.C., Martian isotopic ratios and upper limits for possible minor constituents as derived from Mariner 9 infrared spactrometer data, Icarus, 32, 85-97, 1977.

Manue1, 0.K., A comparison of terrestrial and meteoritic noble gases, in Terrestrial Rare Gases, edited by E.C. Alexander, Jr., and $\mathrm{M}_{\text {. }}$ Ozima, pp. 85-91, Japan Scientific Societies Press, Tokyo, 1978.

Marov, M. Ya., Results of Venus missions, Ann. Rev. Astron.Astrophys., 16, 141-170, $197 \overline{\text {. }}$

Marov, M.Ya., and V.I. Moroz, Preliminary results of studies performed with space probes Venera 9 and Venera 10, Cosmic Research, 14, 573-577, 1976.

Marov, M.Ya., B.V. Byvghev, K.N. Manuilov, Yu.P. Baranov, I.S. Kuznetsov, V.N. Lebedev, V.E. Lystsev, A.V. Maksimov, G.P. Popandopulo, V.A. Razdolin, V。A. Sandimirov, and A.M. Frolov, Nephelometric measurements by the Venera 9 and Venera 10 spacecraft, Cosmic Research, 14, 637-643, 1976.

Martin, T.Z., Mars: Global thermal behavior, in Proceedings Symposium Planetary Atmospheres, Pp. 159-162, Herzberg Institute, Ottawa, Canada, 1977.

Martin, T.Z., and H.H. Kieffer, Thermal infrared properties of the Martian atmosphere. II. The

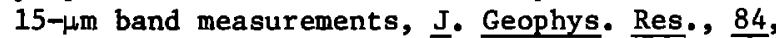
2843-2852, 1979.

Mass, C., and C. Sagan, A numerical circulation model with topography for the Martian southern hemisphere, J. Atmos. Sci., 33, 1418-1430, 1976.

Maxworthy, T., A wave driven model of the Jovian equatorial jet, Planet. Space Sci., 23, 1223$1233,1975$.

Maxworthy, T., and L.G. Redekopp, A solitary wave theory of the Great Red Spot and other observed features in the Jovian atmosphere, Icarus, 29, 261-272, 1976.

Maxworthy, T., L.G. Redekopp, and P.D. Weidman, On the production and interaction of planetary solitary waves: Applications to the Jovian atmosphere, Icarus, 33, 388-409, 1978 。

Mayr, H.G., I. Harris, R.E. Hartle, and W.R. Hoegy, Diffusion model for the upper atmosphere of Venus, J. Geophys. Res., 83, 4411-4416, 1978.

McConnel1, J.C., The ionospheres of Mars and Venus. Ann. Rev. Earth P1anet. Sci., 4, 319-346, 1976.

McElroy, M.B., Y.L. Yung, and A.O. Nier, Isotopic composition of nitrogen: Implications for the past history of Mars' atmosphere, Science, 194, 70-72, 1976a.

McElroy, M.B., T.Y. Kong, Y.L. Yung, and A.O. Nier, Composition and structure of the Martian upper atmosphere: Analysis of results from Viking, Science, 194, 1295-1298, 1976b.

McElroy, M.B., T.Y. Kong, and Y.L. Yung, Photochemistry and evolution of Mars' atmosphere: A
Viking perspective, J. Geophys. Res., 82, 4379$4388,1977$.

Morabito, L.A., S.P. Synnott, P.N. Kupferman, S.A. Collins, Discovery of currently-active extraterrestrial volcanism, Science, 204, 972, 1979.

Moroz, V.I., N.A. Parfent'ev, N.F. San'ko, V.S. Zhegulev, L.V. Zasova, and E.A. Ustinov, Preliminary results of narrow-band photometric probing of the cloud layer of Venus in the $0.80-0.87-1$, spectral region of the Venera 9 and Venera 10 descent vehicles, Cosmic Research, $14,649-662,1976$.

Nagy, A.F., Models of the structure and thermal balance of the Venus ionosphere, in Proceedings Symposium on Planetary Atmospheres, edited by A.V. Jones, pp. 55-56, Herzberg Institute, Ottawa, Canada, 1977.

Newman, W.I., and C. Sagan, Five micron limbdarkening and the structure of the Jovian atmosphere, Icarus, 36, 223-240, 1978.

Nier, A.0., and M.B. McElroy, Composition and structure of Mars' upper atmosphere: Results from the neutral mass spectrometers on Viking 1 and 2, J. Geophys. Res., 82, 4341-4349, 1977. Nier, A.0., M. B.McElroy, and Y.L. Yung, Isotopic composition of the Martian atmosphere, Science, 194, 68-70, 1976.

Nier, A.0., and M.B. McElroy, Structure of the neutra1 upper atmosphere of Mars: Results from Viking 1 and 2, Science, 194, 1298-1300, 1976.

No1t, I.G., W.M. Sinton, L.J. Caroff, E.F. Erickson, D.W. Strecker, and J.V. Radostitz, The brightness temperatures of Saturn and its rings at 39 microns, Icarus, 30, 747-759, 1977.

Ohring, G. and A. Lacser, The ammonta profile in the atmosphere of Saturn from inversion of its microwave emission spectrum, Astrophys. J., 206, $622-626,1976$

0'Leary, B., Venus: Vertical structure of stratospheric hazes from Mariner 10 pictures, J. Atmos. Sc1., 32, 1091-1100, 1975.

orton, G.S., The thermal structure of Jupiter. II. Observations and analysis of 8-14 micron radiation, Icarus, 26, 142-158, 1975.

Orton, G.S., Recovery of the mean Jovian temperature structure from inversion of spectrally resolved thermal radiance data, Icarus, 32, 41-57, 1977.

Orton, G.S., and H.H. Aumann, The abundance of acetylene in the atmosphere of Jupiter, Icarus, $32,431-436,1977$.

orton, G.S., and A.P. Ingersoll, Ploneer 10 and 11 and ground-based infrared data on Jupiter: The thermal structure and $\mathrm{He}-\mathrm{H}_{2}$ ratio, in Jupiter, edited by T. Gehrels, pp. 206-215, University of Arizona Press, 1976.

Orton, G.S., and R.J. Terrile, Multiple frequency sounding of a Jovian cloud, Icarus, 35, 297$307,1978$.

Owen, T., Abundances of isotopes in planetary atmosphere, Moon and P1anets, 19, 297-303, 1978.

Owen, T., and $\mathrm{K}$. Biemann, Composition of the atmoshere at the surface of Mars: Detection of argon-36 and preliminary analysis, Science, $193,801-803,1976$.

Owen, T., K. Biemann, D.R. Rushneck, J.E. Biller, D.W. Howarth, and A.L. Lafleur, The composition of the atmosphere at the surface of Mars, J. Geophys. Res., 82, 4635-4639, 1977.

Oyama, V.I., G.C. Carle, F. Woeller, and J.B. 
Pollack, Venus atmospheric composition analysis by gas chromatography, Sclence, 203, 802-805, 1979.

Ozima, M., and E.C. Alexander, Jr., Rare gas fractionation patterns in terrestrial samples and the Earth-atmosphere evolution model, Rev. Geophys. Space Phys., 14, 385-390, 1976.

Phinney, D., J.Tennyson, and U. Frick, Xenon In $\mathrm{CO}_{2}$ well gas revisited, J. Geophys. Res., 83, 2313-2319, 1978 .

Pilcher, C.B., Evidence for weather on Neptune. II, Astrophys. J., 214, 663-666, 1977.

Pirraglia, J.A., Martian atmospheric lee waves, Icarus, 27, 517-530, 1976.

Podolak, M., Methane rich models of Uranus, Icarus, 27, 473-478, 1976.

Podolak, M., Models of Saturn's interior: Evidence for phase separation, Icarus, 33, 342348, 1978.

Podolak, M., and R.E. Danielson, Axel dust on Saturn and Titan, Icarus, 30, 479-492, 1977.

Podosek, F.A., Isotopic structures in solar system materials, Ann. Rev. Astron. Astrophys., $16,293-334,1978$.

Pollack, J.B., Greenhouse models of the atmosphere of Titan, Icarus, 19, 43-58, 1973.

Pollack, J.B., Mars, Scientific American, 233(3), 106-117, 1975.

Pollack, J.B., and R. Young, Calculations of the radiative and dynamical state of the Venus atmosphere, J. Atmos. Sc1., 32, 1025-1037, 1975.

Pollack, J.B., E.F. Erickson, D. Goorvitch, B.J. Baldwin, D.W. Strecker, F.C. Witteborn, and G.C. Augason, A determination of the composition of the Venus clouds from aircraft observations in the near infrared, J. Atmos. Sci., 32, 1140$1150,1975$.

Pollack, J.B., C.B. Leovy, Y.H. Mintz, and W. VanCamp, Winds on Mars during the Viking season: Predictions based on a general circulation model with topography, Geophys. Res. Lett., 3 , 479-482, 1976.

Pollack, J.B., D. Colburn, R. Kahn, J. Hunter, W. VanCamp, C.E. Carlston, and M.R. Wolf, Properties of aerosols in the Martian atmosphere, as inferred from Viking Lander imaging data, J. Geophys, Res。, 82, 4479-4496, 1977.

Ponnamperuma, $\mathrm{C}_{0}$, The organic chemistry and blology of the atmosphere of the planet Jupiter, Icarus, 29, 321-328, 1976.

Prasad, S.S., L.A. Capone, and L.J. Schneck, Photochemistry of hydrocarbons in the Jovian upper atmosphere, Geophys. Res. Lett., 2, 161-164, 1975.

Prasad, S.S., and L.A. Capone, The photochemistry of amnonia in the Jovian atmosphere, J. Geophys. Res., 81, 5596-5600, 1976.

Price, M.J., Limb brightening on Uranus: An interpretation of the $\lambda 7300 \AA$ methane band, Icarus, 35, 93-98, 1978.

Prinn, R.G., Venus: Chemistry of the lower atmosphere prior to the Pioneer Venus mission, Geophys. Res. Lett., ‥ 973-976, 1978.

Prinn, R.G., and S.S. BaTshay, Carbon monoxide on Jupiter and implications for atmospheric convection, Science, 198, 1031-1034, 1977.

Prinn, R.G., and J.S. Lewis, Phosphine on Juptter and Implications for the Great Red Spot, Science, 190, 274-276, 1975.

Prinn, R.G., and T. Owen, Chemistry and spectro- scopy of the Jovian atmosphere, in Jupiter, edited by T. Gehrels, pp. 319-371, University of Arizona Press, 1976。

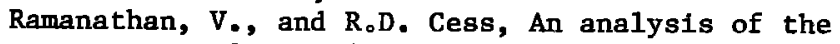
strong zonal circulation within the stratosphere of Venus, Icarus, 25, 89-103, 1975.

Reed, R.A., W.J. Forrest, J.R. Houck, and J.B. Pollack, Venus: The 17- to 38-micron spectrum, Icarus, 33, 554-557, 1978。

Reese, $E$, and $R_{0}$ Beebe, Veloctty varfations of an equatorial plume throughout a Jovian year, Icarus, 29, 225-230, 1976.

Ridgway, S.T., H.P. Larson, and U. Fink, The infrared spectrum of Jupiter, in Jupiter, edited by T. Gehrels, pP. 384-417, University of Arizona Press, 1976.

Rossow, W.B., Cloud microphysics: Analysis of the clouds of Earth, Venus, Mars, and Jupiter, Icarus, 36, 1-50, 1978 .

Russell, R.W., and B.T. Solfer, Observations of Jupiter and Saturn at 5-8 $\mu \mathrm{m}$, Icarus, 30, 282$285,1977$.

Ryan, J.A., and R.M. Henry, Mars atmospher Ic phenomena during major dust storms as measured at surface, J. Geophys. Res., 84, 2821-2829, 1979.

Ryan, J.A., R.M. Henry, S.L. Hess, C.B. Leovy, J.E. Tillman, and $C_{0}$ Walcek, Mars meteorology: Three seasons at the surface, Geophys. Res. Lett., 5, 715-718, 1978.

Sagan, C., The solar system, Scientific American, $233(3), 22-31,1975$.

Sagan, C., and E.E. Salpeter, Particles, environments, and possible ecologies in the Jovian atmosphere, Astrophys. J. Supp1. Ser., 32, 737$755,1976$.

Samuelson, R.E., R.A. Hanel, L。W. Herath, V.G. Kunde, and W.C. Maguire, Venus cloud properties: Infrared opacity and mass mixing ratio, Icarus, 25, 49-63, 1975 .

Schubert, G., C。C. Counselman, III, J. Hansen, S.S. LImaye, G. Pettengill, A。 Selff, I.I. Shapiro, V.E. Suomi, F. Taylor, L. Travis, R. Woo, and R.E. Young, Dynamics, winds, circulation and turbulence in the atmosphere of Venus, Space Sci. Rev., 20, 357-387, 1977.

Seiff, A., and D.B. Kirk, Structure of Mars' atmosphere up to $100 \mathrm{kilometers}$ from the entry measurements of Viking 2, Science, 194, 13001303, 1976.

Seiff, A., and D。B. Kirk, Structure of the atmosphere of Mars in summer at mid-latitudes, J. Geophys. Res., 82, 4364-4378, 1977.

Sill, G.T., The chemistry of the Jovian cloud colors, in Jupiter, edited by T. Gehrels, pp. 372-383, University of Arizona Press, 1976.

Slysh, V.I., Identification of the CO molecule in the radiation spectrum of the Venustan nighttime sky, Cosmic Research, 14, 693-695, 1976.

Smith, B.A., and GoE. Hunt, Motions and morphology of clouds in the atmosphere of Jupiter, in Jupiter, edited by T. Gehrels, pp. 564-585, University of Arfzona Press, 1976.

Smith, B.A., L.A. Sodorblom, T.V. Johnson, A.P. Ingersol1, S.A. Collins, E.M. Schoemaker, G.E. Hunt, H. Masursky, M.H. Carr, M.E. Davies, A.F. Cook, J. Boyce, G.E. Danielson, T. Owen, C. Sagan, R.F. Beebe, J. Veverka, R.G. Strom, J.F. McCauley, D. Morrison, G.A. Briggs, and V.E. Suomi, The Jupiter system through the eyes of Voyager 
I, Science, 204, 951-972, 1979.

Smith, W.H., On the ortho-para equilibrium of $\mathrm{H}_{2}$ in the atmospheres of the Jovian planets, Icarus, 33, 210-216, 1978.

Smoluchowski, $R_{\circ}$, Jupiter, American Scientist, $63,638-648,1975$.

Smoluchowski, R., Origin and structure of Jupiter and its satellites, in Jupiter, edited by $T$. Gehrels, Pp. 61-84, University of Arizona Press, 1976.

Smyth, W.H., and M。B. McE1roy, The sodium and hydrogen gas clouds of Io, Planet. Space Sci. $25,415-431,1977$.

Stone, P.H., The dynamics of the atmosphere of Venus, J. Atmos。 Sci., 32, 1005-1016, 1975.

Stone, P.H., The atmosphere of Uranus, Icarus, 24, 292-298, 1975.

Stone, P.H., The meteorology of the Jovian atmosphere, in Jupiter, edited by T. Gehrels, pp. 586-618, University of Arizona Press, 1976.

Streett, W.B., Phase equilibria in gas mixtures at high pressures, Icarus, 29, 173-186, 1976.

Strobel, D.F., Aeronomy of the major planets: Photochemistry of ammonia and hydrocarbons, Rev. Geophys. Space Phys., 13, 372-382, 1975.

Suomi, V.E., and S.S. Limaye, Venus: Further evidence of vortex circulation, Science, 201, 1009-1011, 1978.

Surkov, Yu.A., Geochemical studies of Venus by Venera 9 and 10 automatic interplanetary stations, Proc. Lunar Sci. Conf. 8, 2665-2689, 1977 .

Sze, N.D., and M.B. McElroy, Some problems in Venus' aeronomy, Planet. Space Sc1., 23, 763$786,1975$.

Taylor, F.W., D.J. Diner, L.S. Elson, M.S。 Hanson, D.J. McCleese, J.V. Martonchik, P.E. Relchley, J.T. Houghton, J. Delderfield, J.T. Schofield, S.E. Bradley, A.P. Ingersol1, Infrared remote sounding of the middle atmosphere of Venus from the Pioneer orbiter, Science, 203, 779-781, 1979.

Teifel, V.G., Estimates of methane and ammonia abundance in the Jovian atmosphere with allowance for scattering in the clouds, Icarus, 30 , 138-154, 1977.

Terrile, R.J., and J.A. Westphal, The vertical cloud structure of Jupiter from $5 \mathrm{hm}$ measurements, Icarus, $30,274-281,1977$.

Terrile, R.Jo, and J.A. Westphal, Infrared imagIng of Jupiter in the 8-14-micrometer spectral region, Icarus, 30, 730-735, 1977.

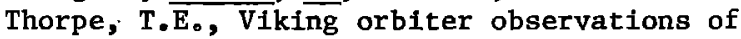
atmospheric opactty during July-November 1976, J. Geophys. Res., 82, 4151-4159, 1977.

Tokunaga, $A_{.}$, and $R_{0} \bar{D}$. Cess, A model for the temperature inversion within the atmosphere of Saturn, Icarus, 32, 321-327, 1977.

Tokunaga, A., R.F. Kracke, and T. Owen, Ethane and acetylene abundances in the Jovian atmosphere, Astrophys。 J., 209, 294-301, 1976.

Tokunaga, A.T., J. CaIdweli, F.C. Gillett, and I.G. No1t, Spatia11y resolved infrared observations of Saturn. II. The temperature enhancement at the south pole of Saturn, Icarus, 36, 216-222, 1978.

Tomasko, M.G., Photometry and polarimetry of Jupiter, in Jupiter, edited by T. Gehrels, pp. 486-515, University of Arizona Press, 1976.

Tomasko, M.G., R. Boese, A.P. Ingersoll, A.A. Lacis, S.S. Limaye, J.B. Pollack, A. Seiff,
A.I. Stewart, V.E。 Suomi, and F.W. Taylor, The thermal balance of the atmosphere of Venus, Space Sci. Rev., 20, 389-412, 1977.

Tomasko, M.G., R.A. West, and N.D. Castillo, Photometry and polarimetry of Jupiter at large phase angles. I. Analysis of imaging data of a prominent belt and a zone from Pioneer 10, Icarus, 33, 558-592, 1978 。

Tomasko, M.G., L.R. Doose, J. Palmer, A。 Holmes, W. Wolfe, N.D。Castillo, P.H. Smith, Preliminary results of the solar flux radiometer experIment aboard the Pioneer Venus Multiprobe mission, Sclence, 203, 795-797, 1979.

Trafton, L.M., Near-infrared spectrophotometry of Titan, Icarus, 24, 443-453, 1975.

Trafton, L., The aerosol distribution in Uranus' atmosphere: Interpretation of the hydrogen spectrum. Astrophys. J., 207, 1007-1024, 1976.

Trafton, L., Uranus' rotational period, Icarus, 32, 402-412, 1977.

Trafton, L., On the deuterium-to-hydrogen ratio in the atmosphere of Uranus, Astrophys. J., 222, 740-743, 1978.

Trafton, L., and W. Macy, Jr., On the distribution of sodium in the vicinity of Io, Icarus, $33,322-335,1978$.

Trauger, J.T., F.L. Roesler, and G. Münch, A redetermination of the Uranus rotation pertod, Astrophys. J., 219, 1079-1083, 1978.

Treffers, R.R., H.P. Larson, U. Fink, and T.N. Gautier, Upper limits to trace consituents in Jupiter's atmosphere from an analysis of its 5- $\mu \mathrm{m}$ spectrum, Icarus, 34, 331-343, 1978.

Turekian, K.K., and S.P. Clark, Jr., The nonhomogeneous accumulation model for terrestrial planet formation and the consequences for the atmosphere of Venus, J. Atmos. Sci., 32, 1257$1261,1975$.

Veverka, J., L.H. Wasserman, J. Elllot, and C. Sagan, The occultation of $\beta$ Scorpii by Jupiter. I. The structure of the Jovian upper atmosphere, Astronom. J., 79, 73-84, 1974.

Walker, J.C.G., Evolution of the atmosphere of Venus, J. Atmos. Sc1., 32, 1248-1256, 1975.

Walker, J.C.G., Evolution of the Atmosphere, Macmillan Publishing Co., Inc., New York, 1977.

Walker, J.C.G., Atmospheric evolution on the inner planets, in Comparative Planetology, edited by C. Ponnamperuma, pp. 141-163, Academic Press, 1978.

Wallace, L., On the thermal structure of Uranus, Icarus, 25, 538-544, 1975.

Wallace, L., The thermal structure of Jupiter in the stratosphere and upper troposphere, in Jupiter, edited by T. Gehrels, pp. 284-303, University of Arizona Press, 1976.

Wallace, L., and D.M. Hunten, The Jovian spectrum in the region $0.4-1.1 \mu \mathrm{m}$ : The $\mathrm{C} / \mathrm{H}$ ratio, $\underline{\mathrm{Rev}}$. Geophys. Space Phys., 16, 289-319, 1978.

Ward, D.B., Far-infrared spectral observations of Saturn and its rings, Icarus, 32, 437-442, 1977.

Webster, P.J., The low-latitude circulation of Mars, Icarus, 30, 626-649, 1977.

Weidenschilling, S.J., and J.S. Lewis, Atmospheric and cloud structures of the Jovian planets, Icarus, 20, 465-476, 1973.

Werner, M.W., G. Neugebauer, J.R. Houck, and M. G. Hauser, One-millimeter brightness temperatures of the planets, Icarus, 35, 289-296, 1978.

Whitten, R.C., L.A. Capone, L. McCulley, and P. 
F. Michelson, The upper atmosphere of Titan, Icarus, 31, 89-96, 1977.

Williams, G.P., P1anetary circulations: I. Barotropic representation of Jovian and terrestrial turbulence, J. Atmos. Sci., 35, 1399$1426,1978$.

Wolfe, J.H., Jupiter, Scientific American, 233(3), 118-129, 1975.

Woo, R., Observations of turbulence in the atmoshpere of Venus using Mariner 10 radio occultation measurements, J. Atmos. Sci., 32, 1084$1090,1975$.

Woodman, J.H., L. Trafton, and T. Owen, The abundances of ammonia in the atmospheres of Jupiter, Saturn, and Titan, Icarus, 32, 314$320,1977$.

Yakovlev, O.I., A.I. Efimov, T.S. Timofeeva, G.D. Yakovleva, E.V. Chub, V.F. Tikhonov, and V.K. Shtrykov, Preliminary radio transmission data and the Venusian atmosphere from Venera 9 and Venera 10, Cosmic Research, 14, 632-637,1976.
Young, A.T., The clouds of Venus, J. Atmos. Sci. 32, 1125-1132, 1975.

Young, A.T., An improved Venus cloud model, Icarus, 32, 1-26, 1977。

Young, A.T., and G.W. Kattawar, Planetary isophotes as a clue to aerosol characteristics. II. Observations of Venus from spacecraft, J. Atmos. Scio, 35, 323-336, 1978.

Young, $A_{.}$, and $\mathrm{L}_{\text {. }}$ Young, Venus, Scientific Amer1can, 233(3), 70-81, 1975.

Young, R.E., and J.B. Pollack, A three-dimensional model of dynamical processes in the Venus atmosphere, J. Atmos. Sci., 34, 1315-1351, 1977.

Yung, Y.L., D.F. Strobel, T.Y. Kong, and M.B. McElroy, Photochemistry of nitrogen in the Martian atmosphere, Icarus, 30, 26-41, 1977.

Zurek, R.W., Diurnal tide in the Martian atmosphere, J. Atmos. Sci., 33, 321-337, 1976

Zurek, R.W., Solar heating of the Martlan dusty atmosphere, Icarus, 35, 196-208, 1978.

\section{INTERPLANETARY DUST}

\section{E. Brownlee}

Small sizes of Individual particles and exceedingly low spatial density are formidable problems which greatly impeded progress in the dust fleld during the previous decade. The major experimental problems which prevented reliable measurements appear finally to have been solved and the entire dust field has seen dramatic progress over the past four years. Major accomplishments were reliable Impact and zodiacal light measurements over the range of solar distance from $0.3 \mathrm{AU}$ to $5 \mathrm{AU}$ and successful collection of micrometeorites from the stratosphere which has provided hundreds of proven interplanetary particles for laboratory studies. Interest in dust has grown because of the increasing realization that the solar system dust cloud is an astrophysical site where grain processes such as radiation pressure, rotational bursting, thermal alteration, ion Implantation, sputtering, and magnetic effects can be studied in-situ. New attention has also been given to dust because dust collection is a practical means of obtaining samples of comets and asteroids.

During the past four years two major information sources on interplanetary dust were published. The proceedings of the IAU Colloquium No. 31 held in Heldelberg was published as Interplanetary Dust and Zodiacal Light: Lecture Notes in Physics 48, edited by H. Elsässer and H. Fechtig. This volume contains 84 papers devoted to dust and is a comprehensive coverage of the fleld up to 1975. The first book devoted entirely to dust is Cosmic Dust, edited by J.A.M. McDonne11 (1978). This work contains 689 pages and is composed of nine lengthy review papers

Copyright 1979 by the American Geophysical Union. which cover major aspects of cosmic dust work.

\section{ORIGIN}

Individual dust particles are quickly destroyed in the interplanetary medium, and it has long been recognized that fresh particles must be continually supplied in order to maintain the solar system's dust cloud in its apparently long lived quasi-equilibrium state. Comets, asterolds, and the interstellar medium are generally belleved to be the most important dust sources, although it has been suggested that the solar photosphere might be a source of submicron particles with exotic compositions [Hemenway, $1975 b$ ].

During the past four years several attempts were made to determine the relative importance of interstellar grains as a dust source. Bertaux and Blamont [1976] suggested that interstellar grains streaming into the solar system may be gravitationally focused to a "downstream" line behind the sun in a manner analogous to the Lyttleton hypothesis for comet formation. The fact that a particle concentration has not been observed in this region led the authors to conclude either that the spatial density of interstellar grains near the solar system is two orders of magnitude below expectation or that the focusing does not occur because of radlation pressure effects or that dust near the solar system is abnormal. Levy and Jokipii [1976] suggested that because interstellar grains are probably charged to a potential of $\sim 3 \mathrm{~V}$, the Lorentz force, caused by interaction with the magnetic field in the solar wind, would prevent 